\title{
v.45, n.4, 2009
}

- In the Contents $-2^{\text {nd }}$ page, $19^{\text {th }}$ line

Where you read A. Hackney change to A. C. Hackney

- Page 751, $4^{\text {th }}$ line

Where you read Anthony Hackney, change to Anthony Carl Hackney

- Pages 752, 754 and 756 in the top

Where you read A. Hackney, change to A. C. Hackney

- Page $854,2^{\text {nd }}$ column, $21^{\text {st }}$ line

Where you read HACKNEY, A. change to HACKNEY, A. C.
The word "toothpaste" must be changed to "paste":

- page 795

- In the Abstract, $1^{\text {st }}, 2^{\text {nd }}, 15^{\text {th }}$ and $16^{\text {th }}$ lines

- In the Uniterms, 1a. line

- page 796

$-2^{\text {nd }}$ column, $12^{\text {th }}$ line and $23^{\text {rd }}$ line

- In the Results, $2^{\text {nd }}$ line and $5^{\text {th }}$ line

-page 797

- In the legend of the TABLE I

- In the $1^{\text {st }}$ column, $6^{\text {th }}$ and $8^{\text {th }}$ line

- In the $2^{\text {nd }}$ column, $4^{\text {th }}$ line

- page 798

- In the $1^{\text {st }}$ column, $34^{\text {th }}$ line, $35^{\text {th }}$ line, $37^{\text {th }}$ line and $46^{\text {th }}$ line

- In the $2^{\text {nd }}$ column, in the CONCLUSION, $3^{\text {rd }}$ line and $4^{\text {th }}$ line 